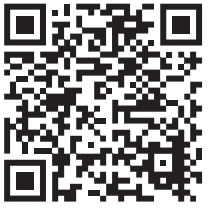

* Médico Pediatra Comisionado Estatal de la Comisión Estatal de Conciliación y Arbitraje Médico del Estado de Tabasco. Coordinador General de la Comisión de Bioética del estado de Tabasco.

Correspondencia: MFT, cecamet@tabasco.gob.mx Conflicto de intereses: El autor declara no tener conflicto de intereses. Citar como: Fernández TM. 23 años de conciliación y arbitraje médico de Tabasco, septiembre 2021. Rev CONAMED. 2021; 26(4): 170-172. https://dx.doi. org/10.35366/102503 Financiamiento: Sin financiamiento.

Recibido: 29/10/2021. Aceptado: 29/10/2021.

\section{3 años de conciliación y arbitraje médico de Tabasco, septiembre 2021}

\author{
23 years of conciliation and medical arbitration of Tabasco, September 2021 \\ Manuel Fernández Torrano*
}

Entre las décadas de los 80 y 90 en Tabasco, La relación médico-paciente se fue tensando de manera peligrosa y creciente, dado que la única vía de solucionar las controversias entre médico-paciente era la judicialización, aunque más de una vez, se tomó justicia por mano propia. Los médicos consideraban que el hecho que no fueran pares quienes analizaran su comportamiento en el ámbito específico de la ciencia médica, los dejaba en cierta forma en indefensión, por lo que se buscaron diversas opciones de mediación.

El 25 de febrero de 1997 se crea la Comisión Estatal de Arbitraje Médico (CEAM), con el acuerdo de creación 11027, siete meses después de la instauración de la Comisión Nacional de Arbitraje Médico (CONAMED); posteriormente, el 20 de marzo de 2002, con el decreto 064, se emite la ley de creación de la Comisión Estatal de Conciliación y Arbitraje Médico (CECAMET), como un organismo público descentralizado que, por su disposición a través de Conciliación y Arbitraje, ${ }^{2}$ se conoció como el Modelo Tabasco de Arbitraje Médico. ${ }^{3}$ El 22 de julio del 2009 se publica el reglamento de atención de quejas, conciliación y arbitraje médico de la (CECAMET), que integra las audiencias informativas, diligencias a las cuales asisten únicamente los médicos que son requeridos por la sociedad, y se les informa los pormenores de la inconformidad planteada y los posibles alcances jurídicos. ${ }^{4}$

En el periodo 2020-2021, época de la pandemia por SARS-CoV-2, se constituyó un programa de capacitación, enseñanza, promoción y difusión, como el expediente clínico con 1,953 asistentes, el acto médico con 932 asistentes y la seguridad del paciente con 511. En nuestras redes sociales tenemos un total aproximado de 7,300 seguidores. ${ }^{5}$

\section{DATOS ESTADÍSTICOS}

1. Asesorías y orientaciones (Figuras 7 a 3):6

a. Asesorías: éstas observan un incremento en 1998, y 2007, con un posterior descenso 2008-2009, ascendiendo a un 18\% en el 2020. 


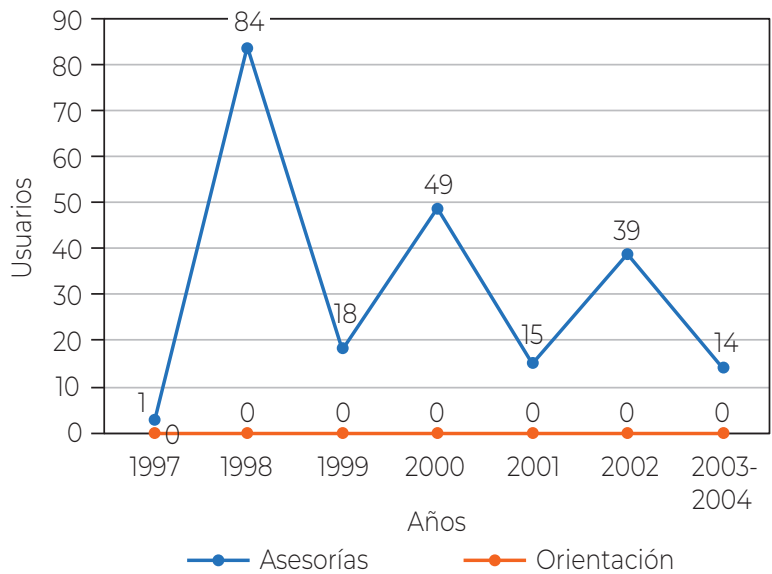

Figura 1: Estadística de la Comisión Estatal de Conciliación y Arbitraje Médico (CECAMET) 1997-2004.

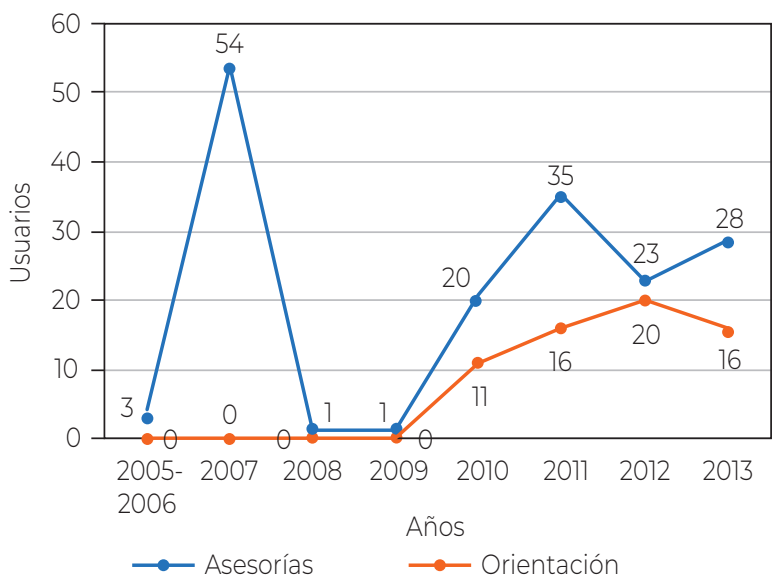

Figura 2: Estadística de la Comisión Estatal de Conciliación y Arbitraje Médico (CECAMET) 2005-2013.

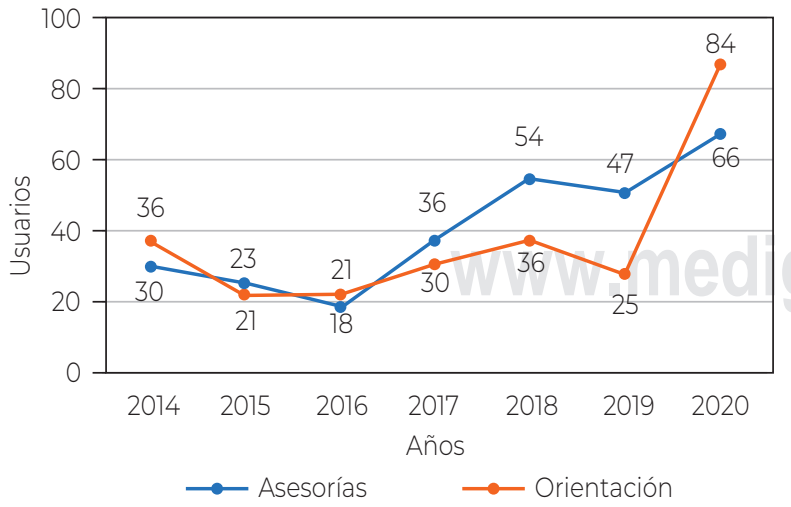

Figura 3: Estadística de la Comisión Estatal de Conciliación y Arbitraje Médico (CECAMET) 2014-2020.

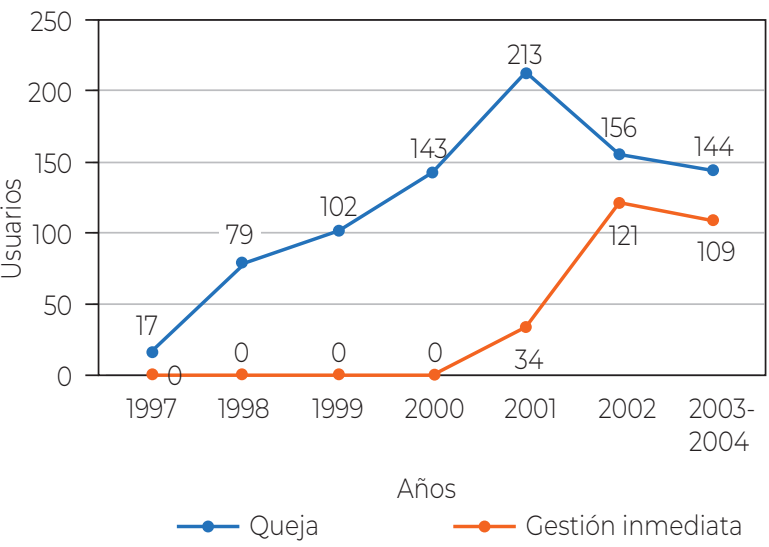

Figura 4: Estadística de la Comisión Estatal de Conciliación y Arbitraje Médico (CECAMET) 1997-2004.

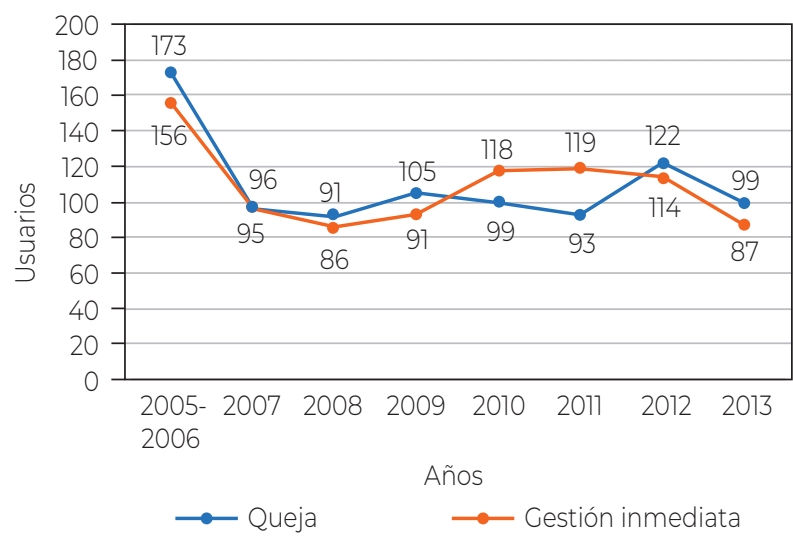

Figura 5: Estadística de la Comisión Estatal de Conciliación y Arbitraje Médico (CECAMET) 2005-2013.

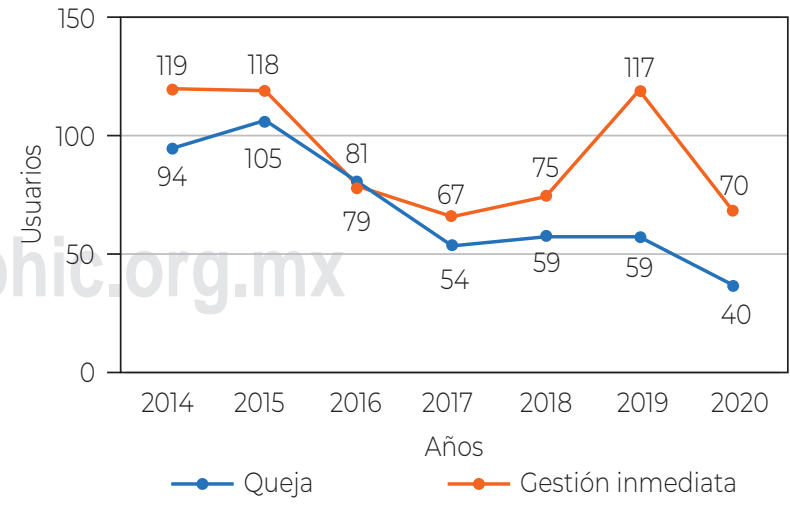

Figura 6: Estadística de la Comisión Estatal de Conciliación y Arbitraje Médico (CECAMET) 2014-2020. 
b. Orientaciones: esta acción inicia a partir del 2010, presentando un incremento del 73\%, en el 2020.

2. Gestiones y quejas (Figuras 4 a 6 ): ${ }^{6}$

a. Quejas: observan incremento en 1997, hasta el 2001 (196\%), con descenso a un 114\% en el 2020.

b. Gestiones inmediatas: éstas iniciaron el 2001, observándose un repunte en el 2002 (87\%), descendiendo a un 51\% en el 2020.

\section{REFERENCIAS}

1. Fajardo-Dolci C, Hernández-Torres F (coeditores). El arbitraje médico en México a través de sus comisiones, 15 años de experiencia. México: CONAMED; 2011.

2. Comisión Nacional de Arbitraje Médico (CONAMED). 20 años de arbitraje médico. Ciudad de México, México: Secretaría de Salud; 2016

3. CECAMET. Segundo Informe de labores. 2003. p. 5.

4. CECAMET. Primer Informe de Labores. 2000. pp. 18-20.

5. CECAMET. Informe Anual de Conciliación y Arbitraje Médico del estado de Tabasco. 2020. pp. 14-20.

6. Sistema Nacional de Registro de la Queja Médica (SAQMED). 2021. 